\title{
Spontaneous Passage of a Long Nail through the Gastrointestinal Tract of a 2-year old Child: A Case Report
}

Chukwubuike Kevin Emeka

Pediatric Surgery Unit, Department of Surgery, Enugu State University Teaching Hospital, Enugu, Nigeria.

Correspondence: Chukwubuike Kevin Emeka, Department of Surgery, Enugu State University Teaching Hospital, Enugu, Nigeria.

Received Date: April 03, 2021; Accepted Date: April 20, 2021; Published Date; July 19, 2021

Citation: Chukwubuike Kevin Emeka. (2021) Spontaneous Passage of a Long Nail through the Gastrointestinal Tract of a 2-year old Child: A Case Report. J. Surg Case Repo and Imag. 4(5); DOI:10.31579/2690-1897/070

Copyright: (C) 2021 Chukwubuike Kevin Emeka, This is an open-access article distributed under the terms of the Creative Commons Attribution License, which permits unrestricted use, distribution, and reproduction in any medium, provided the original author and source are credited

\begin{abstract}
Swallowing of foreign body is a common problem in children. Although most foreign bodies in the gastrointestinal tract will pass spontaneously, passage of sharp and pointed object such as a long nail is unusual. We report a case of a 2-year old female who swallowed a 3-inch nail and passed the nail per rectum spontaneously without problems while preparations were being made for the removal of the nail. The rarity of this event makes it worthy of being reported.
\end{abstract}

Keywords: gastrointestinal tract; long nail

\section{Introduction}

Foreign body in the gastrointestinal tract is a common problem frequently encountered in children and this problem is seen in children emergency units all over the world [1]. Coins are the most commonly ingested foreign body in children in the United States of America: In other countries where coins are not commonly used, fish bone is the most common [2]. The peak age range in which foreign body ingestion occurs is 6 months to 3 years [3]. The highest risk of foreign body ingestion is seen in children with mental health challenges and in those with gastrointestinal abnormalities such as previous surgery and strictures [4]. Majority of the swallowed foreign bodies will pass through the gastrointestinal tract without problems. However, pointed objects such as pins and nails may traumatize the wall of the intestinal tract causing complications such as obstruction or perforation [5]. The most likely sites of foreign body impaction are the gastric pylorus and ileocecal valve [6]. Ingestion of foreign body in children entails the child exploring the object with his/her mouth and accidentally swallowing the object. This incident may or may not be witnessed by an adult. The symptoms of foreign body in the gastrointestinal tract may include abdominal pain and/or vomiting. Howbeit, the presence of foreign body in the gastrointestinal tract may not elicit any symptoms. An imaging study is necessary as part of clinical evaluation of the patient [7]. Most foreign body will show on plain radiograph. Even radiolucent objects may be identified by their edges and irregularity on the radiograph [2]. We report a case of a 2-year old female who swallowed a 3-inch nail and passed the nail spontaneously. The interest in this article is its rarity and spontaneous passage of such pointed large foreign body in the gastrointestinal tract.

\section{Case Presentation}

A 2-year old girl presented through the children emergency room with a history of having swallowed a nail, 24 hours prior to presentation. The swallowing of the nail was witnessed by an older child who informed the child's parents. Although there were no symptoms, anxiety and apprehension on the part of the parents prompted presentation to the hospital. On examination, the patient was fully conscious, afebrile, not pale, not jaundiced, not dehydrated. Pulse rate was 88 beats per minute, blood pressure $100 / 60 \mathrm{mmHg}$, respiratory rate 22 cycles per minute, temperature $36.7^{\circ} \mathrm{c}$. Chest and abdominal examination revealed no abnormality clinically. Plain abdominal $x$ ray showed the a long nail lying transversely in the intestine (Figure 1). 


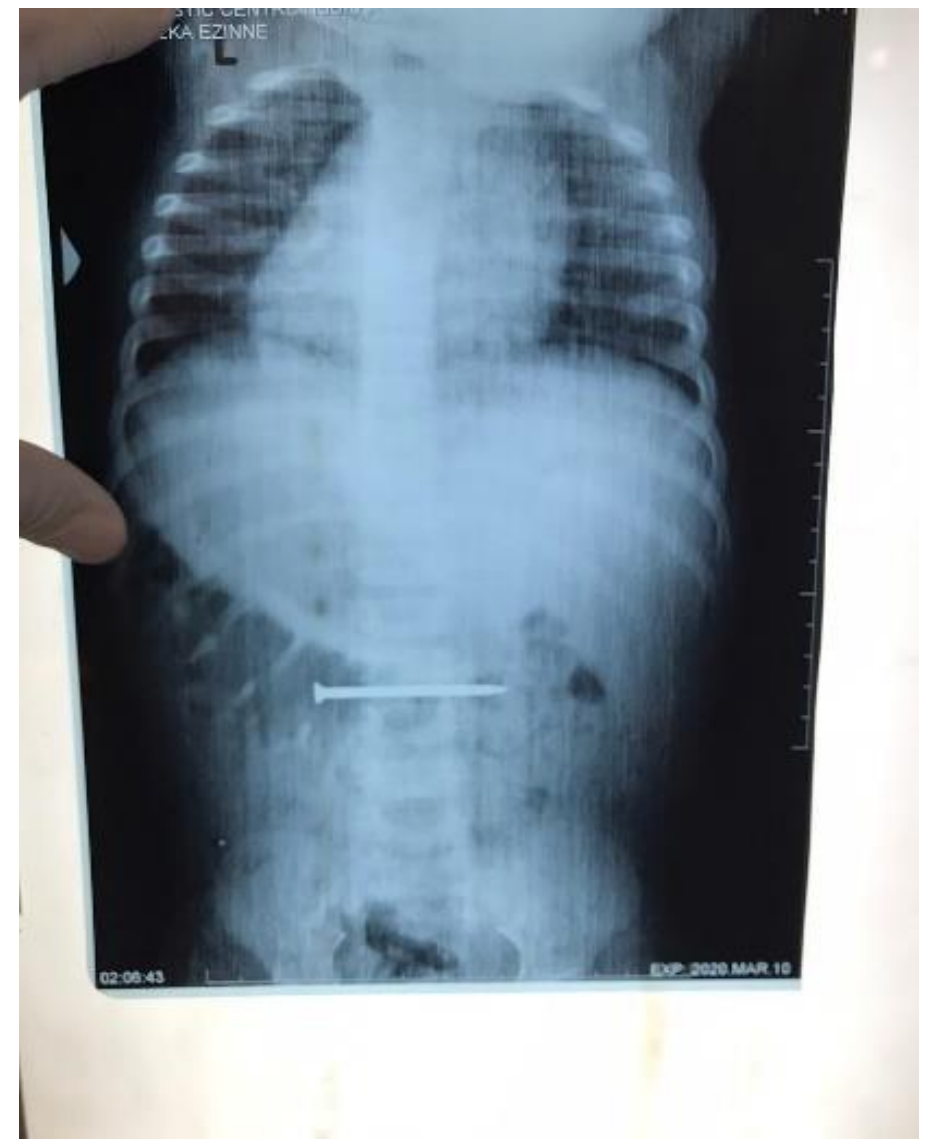

\section{Figure 1: Plain abdominal $x$ ray of the index patient}

Hematological and biochemical investigations done were all within normal range. Arrangements were made for endoscopic removal of the nail from the gastrointestinal tract but this could not happen due to financial constraints and logistic problems. On the second day of admission, the patient was noticed to have passed the long nail per rectum (Figure 2).

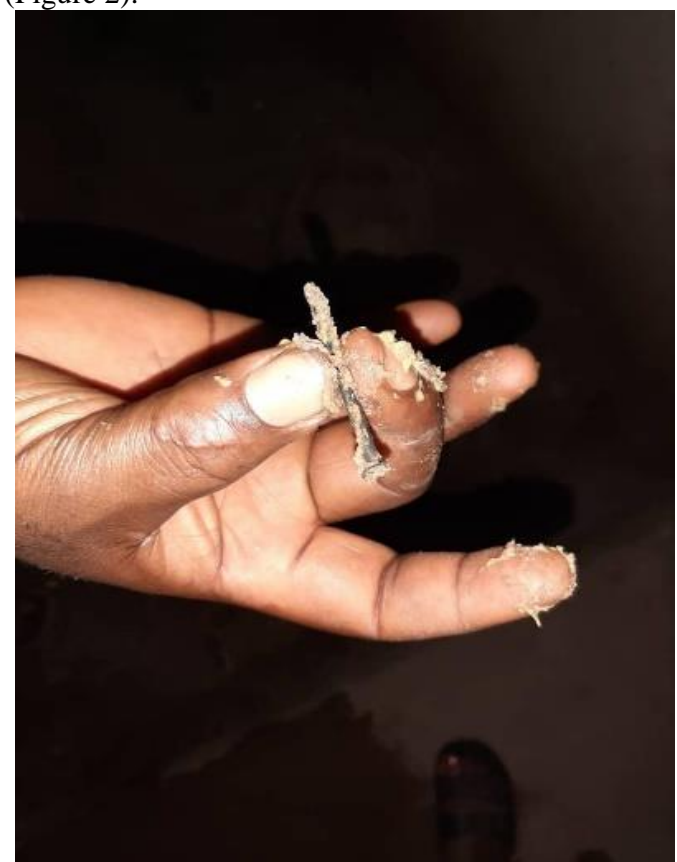


The patient was observed in the hospital for 48 hours and was subsequently discharged home. She has been followed up for 6 months in the outpatient clinic and there are no complaints.

\section{Discussion}

Foreign body ingestion is more common amongst the pediatric age group than in the adult population [8]. This is in contrast to foreign body insertion through the anus, where adults with psychiatric disorders insert objects like pens and plastics into their rectum [8]. Foreign body in the gastrointestinal may be classified based on location into gastric, intestinal or colorectal. Classification may also be done based on the nature of the foreign body into blunt objects, sharp pointed objects and objects containing poisons. Using the above classification criteria, the index patient had an intestinal sharp pointed object.

Uyemura et al in their series reported that the peak age of children who swallow foreign body is 6 months to 3 years [9]. This finding is consistent with the age of the patient in the present case report. However, Arango et al reported that foreign body ingestion is highest in children less than 5 years of age [10]. It is worthy to note that foreign body ingestion can occur at any age. Psychological issue in a child is a known risk factor for foreign body ingestion [4]. Ingestion of foreign body may not be witnessed by the parents and the foreign body may be seen incidentally during evaluation for unexplained fever or weight loss [2]. This is in contrast to the finding in the index patient where the ingestion was witnessed by an older child. There were no symptoms in our patient. One series reported the presence of symptoms in 50 percent of the children who swallowed foreign body, even when the ingestion of the foreign body was witnessed [11]. The presence of symptoms may be related to the development of complications such as impaction, obstruction or perforation.

Clinical examination of a patient with foreign body in the gastrointestinal tract may not reveal any abnormality [2]. However, certain swallowed foreign bodies such as nickel may cause systemic symptoms like rash in patients with sensitivity reactions [2].

Imaging investigation is an integral part of the evaluation of children who swallow foreign body. Most foreign bodies such as coins and nails are radiopaque and will show on radiograph. Radiolucent objects such as meat bolus may require computed tomography (CT) scan and magnetic resonance imaging (MRI). However, cost, exposure to radiations and nonavailability of these imaging modalities limit the use of these investigations in children. Eighty to ninety percent of the foreign bodies in the gastrointestinal tract will pass through without problems [10]. Howbeit, sharp and pointed objects like nails rarely pass without causing problems. Hence, the need to report this uncommon condition and create awareness on the possibility of spontaneous passage of such objects.

\section{References}

1. Bekkerman M, Sachdev AH, Andrade J, Twersky Y, Iqbal S. (2016). Endoscopic Management of Foreign Bodies in the Gastrointestinal Tract: A Review of the Literature. Gastroenterol Res Pract;2016:8520767. doi: 10.1155/2016/8520767

2. Conners GP, Mohseni M. (2020). Pediatric Foreign Body Ingestion. In: StatPearls [Internet]. Treasure Island (FL): StatPearls Publishing;

3. Uyemura MC. (2006). Foreign body ingestion in children. Am Fam Physician; 73(8): 1332.

4. Prasad V, Samuel V, Ramakrishnan M, Ravikumar D, Sharma N. (2018). Management of foreign body ingestion in children with cerebral palsy: Need for proper trauma management protocol. $J$ Family Med Prim Care; 7(3): 638-641. doi: 10.4103/jfmpc.jfmpc_91_18

5. Lavin JM, Wiedermann J, Sals A, Kato K, Brinson D, et al. (2018). Electronic medical record-based tools aid in timely triage of disc-shaped foreign body ingestions. Laryngoscope;128(12): 2697-2701. doi: 10.1002/larv.27279.

6. Pavlidis TE, Marakis GN, Triantafyllou A, Psarras K, Kontoulis TM. (2008). Management of Ingested Foreign Bodies. How Justifiable is a Waiting Policy? Surg Laparosc Endosc Percutan Tech; 18(3): 286-287. doi: 10.1097/SLE.0b013e31816b78f5

7. Pugmire BS, Lim R, Avery LL. (2015). Review of Ingested and Aspirated Foreign Bodies in Children and Their Clinical Significance for Radiologists. Radiographics; 35(5): 1528-1538. doi: 10.1148/rg.2015140287

8. Obinwa O, Cooper D, James M. Gastroinrestinal Foreign Bodies, Actual Problrms of Emergency Abdominal Surgery, Dmitry Victorovich Garbuzenko. IntechOpen; doi: 10.5772/63464

9. Uyemura MC. (2006). Foreign body ingestion in children. Am Fam Physician; 73(8): 1332

10. Arango AA, Leon LP, Martinez DC, Jurado GM. (2011). Incidental foreign body in the gastrointestinal tract: Report of three cases and literature review. Rev Col Gastroenterol; 26(4): 316-327.

11. Arana A, Hauser B, Hachimi-Idrissi S, (2001). Management of ingested foreign body in childhood and review of the literature. Eur J Pediatr; 160: 468-472. doi: 10.1007/s004310100788.

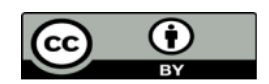

This work is licensed under Creative Commons Attribution 4.0 License
Ready to submit your research? Choose Auctores and benefit from:

*ast, convenient online submission
*igorous peer review by experienced research in your field
*apid publication on acceptance
* authors retain copyrights
* immique DOI for all articles
immediate, unrestricted online access

At Auctores, research is always in progress.

Learn more www.auctoresonline.org/journals/journal-of-surgical-casereports-and-images 